TITLE:

\title{
Plastic deformation of single crystals of Ti5Si3 with the hexagonal D88 structure
}

\section{$\operatorname{AUTHOR}(S)$ :}

Kishida, Kyosuke; Fujiwara, Masakazu; Adachi, Hiroki; Tanaka, Katsushi; Inui, Haruyuki

\section{CITATION:}

Kishida, Kyosuke ...[et al]. Plastic deformation of single crystals of Ti5Si3 with the hexagonal D88 structure. Acta Materialia 2010, 58(3): 846-857

\section{ISSUE DATE:}

2010-02

URL:

http://hdl.handle.net/2433/102267

\section{RIGHT:}

c 2009 Acta Materialia Inc.; この論文は出版社版でありません。引用の 際には出版社版をご確認ご利用ください。; This is not the published version. Please cite only the published version. 


\title{
Plastic deformation of single crystals of $\mathrm{Ti}_{5} \mathrm{Si}_{3}$ with the hexagonal $\mathrm{DB}_{8}$ structure
}

Kyosuke KISHIDA, Masakazu FUJIWARA, Hiroki ADACHI, Katsushi TANAKA and Haruyuki INUI

Department of Materials Science and Engineering, Kyoto University

Sakyo-ku, Kyoto 606-8501, JAPAN

\begin{abstract}
The deformation behavior of $\mathrm{Ti}_{5} \mathrm{Si}_{3}$ single crystals with the hexagonal $\mathrm{D} 8_{8}$ structure has been investigated in compression as a function of crystal orientation in a temperature range from 1200 to $1500^{\circ} \mathrm{C}$. Three different types of deformation modes: $\{1 \overline{1} 00\}[0001]$ prismatic slip, $\{2 \overline{11} 2\} 1 / 3<2 \overline{113}>$ pyramidal slip and $\{2 \overline{11} 8\}<8 \overline{443}>$ twinning were identified for the first time as being operative in $\mathrm{Ti}_{5} \mathrm{Si}_{3}$ at temperatures above $1300^{\circ} \mathrm{C}$, depending on the loading axis orientation. The critical resolved shear stresses (CRSS) decrease steeply with increasing temperature for all deformation modes. The values of the CRSS for $\{1 \overline{1} 00\}[0001]$ prismatic slip are considerably lower than those for $\{2 \overline{11} 2\} 1 / 3<2 \overline{113}>$ pyramidal slip, but are comparable to those for $\{2 \overline{11} 8\}<8 \overline{443}>$ twinning. The favored deformation modes are discussed on the basis of anisotropic elasticity theory of dislocations.
\end{abstract}

Keywords: Transition-metal silicides; Deformation behavior; Dislocation structures; Twinning; Mechanical properties

Corresponding author: Kyosuke KISHIDA

Department of Materials Science and Engineering, Kyoto University, Sakyo-ku, Kyoto 606-8501, JAPAN

E-mail address: k.kishida@materials.mbox.media.kyoto-u.ac.jp

Tel.: +81-75-753-5481; fax: +81-75-753-5461 


\section{Introduction}

There is a growing interest in reducing global warming. The reduction of $\mathrm{CO}_{2}$ emission from turbine engines in existing power plants is believed to be very efficient in the suppression of global warming, when referring to the fact that more than $30 \mathrm{vol} \%$ of $\mathrm{CO}_{2}$ emission is from power generation. This can be achieved by improving the efficiency of turbine engines of stationary power plants. One of the ways to achieve this goal is to develop structural materials capable of operating in severe oxidizing atmosphere and at temperatures much higher than the maximum operation temperatures of Ni-based superalloys. A number of candidate materials including intermetallic alloys such as $\mathrm{NiAl}$ have been investigated in the last two decades [1]. While many candidate materials do not withstand the target operating temperatures approaching $1500^{\circ} \mathrm{C}$, there are still research activities on transition-metal silicides, mostly because of their very high melting temperatures. The early studies on these structural silicides were focused on transition-metal disilicides, especially on $\mathrm{MoSi}_{2}$, mainly due to their excellent oxidation resistance at elevated temperatures [2-4]. Once alloys based on $\mathrm{MoSi}_{2}$ was proved to have serious limitations with respect to fracture toughness and ductility at ambient temperatures, however, alloys based on transition-metal silicides with a general formula of $\mathrm{M}_{5} \mathrm{Si}_{3}$ ( $\mathrm{M}=$ transition-metal) that exhibit higher melting temperatures have become the subject of extensive study. These include those based on $\mathrm{Mo}_{5} \mathrm{Si}_{3}, \mathrm{Ti}_{5} \mathrm{Si}_{3}$ and $\mathrm{Nb}_{5} \mathrm{Si}_{3}$. In particular, $\mathrm{Nb}_{5} \mathrm{Si}_{3}$ has been extensively investigated in the form of $\mathrm{Nb} / \mathrm{Nb}_{5} \mathrm{Si}_{3}$ in-situ composites for high-temperature structural applications in aerospace propulsion [5]. Although their oxidation resistance is generally poor at about $800^{\circ} \mathrm{C}$ and above, the oxidation stability of $\mathrm{Mo}_{5} \mathrm{Si}_{3}$ and $\mathrm{Ti}_{5} \mathrm{Si}_{3}$ was found to be improved drastically by small additions of third elements [6,7]. A significant effort of research has been devoted to the development of Mo- $\mathrm{Mo}_{5} \mathrm{Si}_{2} \mathrm{~B}$ (the so-called T2 phase) alloys [8,9]. When compared $\mathrm{Mo}_{5} \mathrm{Si}_{3}$-based alloys with $\mathrm{Ti}_{5} \mathrm{Si}_{3}$, a less significant effort has been made in the development of alloys based on $\mathrm{Ti}_{5} \mathrm{Si}_{3}$, in spite of its high melting temperature $\left(2130{ }^{\circ} \mathrm{C}\right)$, low density $\left(4.32 \mathrm{~g} / \mathrm{cm}^{3}\right)$ and good oxidation resistance [10-12].

$\mathrm{Ti}_{5} \mathrm{Si}_{3}$ has a complex hexagonal structure which refers to the $\mathrm{Mn}_{5} \mathrm{Si}_{3}$ type of structure (D8 ${ }_{8}$ structure in the Schoenflies notation) with the space group $P 6_{3} / \mathrm{mcm}$. The crystal structure is characterized by two distinct atomic chains extending along the $c$-axis, as shown in Fig. 1. One is a linear chain which consists of metal atoms $A(1)$ located at $(1 / 3,2 / 3, z)$ where $\mathrm{z}=0,1 / 2$. These $\mathrm{A}(1)$ atoms are coordinated by six Si atoms which, in turn, form irregular polyhedra. The other linear chain possesses $\mathrm{A}(2)$ atoms of trigonal antiprisms in the corners of the unit cell. The silicon atoms form interchain bonds between the $A(1)$ and $A(2)$ atoms to tie together the structure. Because of the complex crystal structure, $\mathrm{Ti}_{5} \mathrm{Si}_{3}$ is expected to have limitations with respect to fracture toughness and ductility at ambient temperatures in the monolithic form. Indeed, most studies on this silicide have focused on utilizing the silicide as a strengthening phase in composite forms [10,13-17], except the work of Frommeyer et al. [10] and Umakoshi and Nakashima [11]. Frommeyer et al. [10] concluded that deformation of polycrystalline $\mathrm{Ti}_{5} \mathrm{Si}_{3}$ occurring only above $1000{ }^{\circ} \mathrm{C}$ is carried by thermally activated slip and twinning. Umakoshi and Nakashima [11] later reported that deformation twinning of the $\{1 \overline{1} 02\}<\overline{1} 101>$-type is operative in single crystals with some limited loading axis orientations at high temperature above $1300{ }^{\circ} \mathrm{C}$ in compression. But, neither other slip systems nor their critical resolved shear stresses have been quantitatively identified for $\mathrm{Ti}_{5} \mathrm{Si}_{3}$. Hence, almost nothing is known about the deformation mechanisms of $\mathrm{Ti}_{5} \mathrm{Si}_{3}$ in the monolithic form.

In the present study, we investigate the plastic deformation behavior of single crystals of $\mathrm{Ti}_{5} \mathrm{Si}_{3}$ in compression as a function of crystal orientation and temperature, in order to deduce the operative deformation modes and their related flow stresses. 


\section{Experimental Procedure}

Single crystals of $\mathrm{Ti}_{5} \mathrm{Si}_{3}$ with a nominally stoichiometric composition of Ti-37.5 at\%Si were grown with an optical floating zone (FZ) furnace at a growth rate of $6 \mathrm{~mm} / \mathrm{h}$ in an Ar gas flow. X-ray diffraction confirmed that the lattice parameters of the as-grown crystals are: $a=$ $0.7458 \mathrm{~nm}$ and $c=0.5152 \mathrm{~nm}$. These are in good agreement with those previously reported for $\mathrm{Ti}_{5} \mathrm{Si}_{3}$ of very high-purity [18], indicating the exact stoichiometry and the high quality of the single crystals.

After determining the crystallographic orientations by the X-ray back-reflection Laue method, specimens with a rectangular parallelepiped shape having three orthogonal faces parallel to the (0001), $(11 \overline{2} 0)$ and $(1 \overline{1} 00)$ planes with the dimensions of $3.115 \times 3.037 \times 3.401$ $\mathrm{mm}^{3}$ were cut from the crystals by spark-cutting. Then, the specimen surface was mechanically polished with $0.3 \mu \mathrm{m}$ alumina abrasive powders. Measurements of the elastic constants were carried out by the rectangular parallelepiped resonance (RPR) method at room temperature. In this method, all elastic constants are derived from the frequencies of resonance vibrations of specimen [19]. The resonance data are recorded over a frequency range from 550 to $1650 \mathrm{kHz}$. The first 40 resonance peaks are used to determine the elastic constants.

Oriented single crystalline specimens for compression tests with dimensions of $1.5 \mathrm{x}$ $1.5 \times 4 \mathrm{~mm}^{3}$ were sectioned from the as-grown single crystals by spark-cutting. All specimens were mechanically polished and then finished with $0.3 \mu \mathrm{m}$ alumina abrasive powders prior to compression tests. The orientations of the single crystals were determined by the X-ray

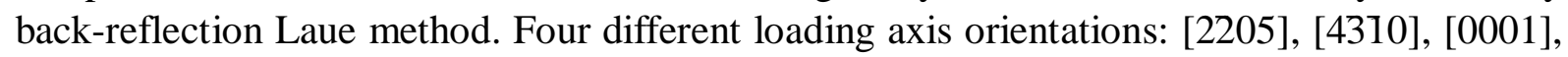
and [ $\left.2 \begin{array}{lll}2 & 1 & 24\end{array}\right]$ were selected, as shown in Fig. 2. The highest Schmid factors of the possible deformation modes are listed up in Table 1 for each orientation. The deformation modes of Table 1 were selected on the basis of elementary dislocation theory that the slip systems with a higher $d / b$ value ( $d$ and $b$ stand, respectively, for the slip plane spacing and the magnitude of Burgers vector) tend to be preferred to operate. Compression tests were carried out in vacuum by using an Instron-type testing machine at a strain rate of $\dot{\varepsilon}=1 \times 10^{-4} \mathrm{~s}^{-1}$ at temperatures ranging from 1200 to $1500{ }^{\circ} \mathrm{C}$. Deformation structures were examined by optical microscopy (OM), scanning electron microscopy (SEM) and transmission electron microscopy (TEM).

\section{Results}

\subsection{Elastic constants at room temperature}

The values of single-crystal elastic constants $\left(c_{\mathrm{ij}}\right)$ determined at room temperature are tabulated in Table 2 together with the elastic anisotropy parameters $\left(c_{33} / c_{11}\right.$, $\left(c_{11}+c_{33}-2 c_{13}\right) / 4 c_{44}$ and $\left.c_{44} / c_{66}\right)$. As exemplified with the values close to unity for all anisotropic parameters $\left(c_{33} / c_{11}=0.94,\left(c_{11}+c_{33}-2 c_{13}\right) / 4 c_{44}=1.20\right.$ and $\left.c_{44} / c_{66}=1.04\right)$, the values of $c_{\mathrm{ij}}$ obtained for $\mathrm{Ti}_{5} \mathrm{Si}_{3}$ have characteristics typically observed in many hexagonal crystals, except that the value of $c_{12}$ is quite different from that of $c_{13}$. The values for Cauchy pressure estimated are 16.7 and -39.6 for $c_{12}-c_{66}$ and $c_{13}-c_{44}$, respectively. The negative value of Cauchy pressure may indicate the directionality of atomic bonding, as in the case of cubic crystals [20]. Polycrystalline isotropic elastic moduli are evaluated from the single-crystal stiffness constants by the Hill's method [21], in which the elastic moduli are estimated as the average of Voigt and Reuss limits, as tabulated in Table 3. The values of bulk $(B)$, shear $(G)$ and Young's moduli $(E)$ are estimated to be 140, 96 and 234 GPa, respectively. The value of polycrystalline Young's modulus (234 GPa) determined in the present study is larger by about $50 \%$ than that $\left(156 \mathrm{GPa}\right.$ ) reported previously for a $\mathrm{Ti}_{5} \mathrm{Si}_{3}$ polycrystalline specimen [10]. The orientation dependence of Young's modulus on (1100) prism plane is depicted in Fig. 3. The value of Young's modulus is the largest along the $c$-axis $\left(E_{/ / 0001}=254\right.$ $\mathrm{GPa})$ and exhibits a minimum $\left(E_{\min }=225 \mathrm{GPa}\right)$ along a direction about 50 degrees away from 
the $c$-axis. Since the largest value differs from the smallest only by $10 \%$, the Young's modulus of $\mathrm{Ti}_{5} \mathrm{Si}_{3}$ is virtually orientation independent. This may be caused by the very complex crystal structure of $\mathrm{Ti}_{5} \mathrm{Si}_{3}$. The significantly smaller value of Young's modulus reported previously for $\mathrm{a} \mathrm{Ti}_{5} \mathrm{Si}_{3}$ polycrystalline specimen [10] cannot then be attributed to texture effects. We suspect that some elastically soft phases such as $\mathrm{Ti}$ were incorporated in the $\mathrm{Ti}_{5} \mathrm{Si}_{3}$ polycrystalline specimens [10]. The value of Poisson's ratio ( $v$ ) is very small at about $v=0.22$, indicating the brittleness. In fact, the value of $B / G$ ratio is 1.46 , being far smaller than the value (1.75), above which the material is predicted to be ductile according to the Pugh's criterion [22].

\subsection{Stress-strain behavior}

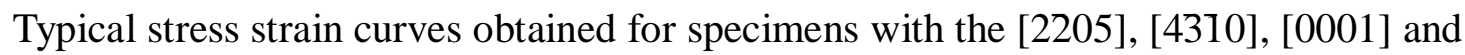
[2 $\overline{1} \overline{1}$ 24] orientations are shown in Figs. 4(a), (b) (c) and (d), respectively. The symbol $\times$ in the figure indicates the occurrence of failure in the elastic region without any appreciable

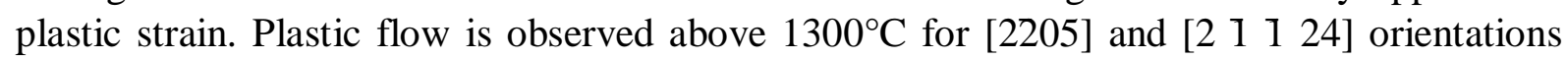
and above $1400^{\circ} \mathrm{C}$ for [4 $\overline{31} 0$ ] and [0001] orientations. The stress-strain curves for plastically deformed samples generally exhibit a yield drop followed by a gradual decrease in flow stress. The amount of yield drop decreases with increasing temperature for [2 $\overline{2} 05]$ and [4 $\overline{31} 0]$ orientations. A similar yield drop behavior is observed in many transition-metal silicides [23-25] and in covalent semiconductors [26]. This is attributed to the fact that the stress required to generate dislocations is much larger than that required for their motion because of a quite low density for grown-in dislocations. Fig. 5 shows the temperature dependence of the yield stress for four different orientations investigated. The values of the yield stress for these four orientations decrease monotonously with increasing temperature.

\subsection{Deformation structures}

\subsection{1. [22̄05] orientation}

Fig. 6 shows deformation markings observed on two orthogonal surfaces of $\mathrm{Ti}_{5} \mathrm{Si}_{3}$

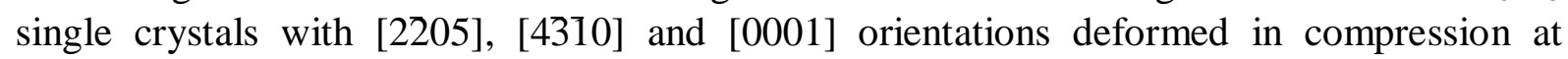

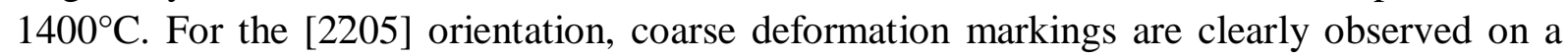
(5504) surface whereas they are very faint on the (1120) surface (Fig. 6(a)). Trace analysis has confirmed that the markings are parallel to the trace of the $(1 \overline{1} 00)$ prismatic plane. The faint traces on the (1120) surface suggest that the slip direction is parallel to [0001], which is on the (1120) surface. Fig. 7 illustrates the result of TEM analysis made to determine the Burgers

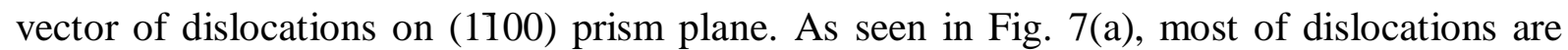
aligned parallel to [ $\overline{11} 20]$ and to $<\overline{11} 23>$ in a TEM foil cut parallel to the (1100) slip plane. A dislocation visible in Figs. 7(b) and (c) is invisible when the diffraction vectors (g) are $03 \overline{3} 0$ (Fig. 7(d)) and $21 \overline{3} 0$ (Fig. 7(e)). The Burgers vector (b) of the dislocation is thus confirmed to be parallel to [0001] based on the standard $\mathbf{g} \cdot \mathbf{b}$ rule. The magnitude of the dislocation Burgers vector are also determined by the thickness fringe method [27] which utilizes the fact that the dot product of $\mathbf{g}$ and $\mathbf{b}$ (i.e., $\Delta n=\mathbf{g} \cdot \mathbf{b})$ corresponds to the number of the extra fringes $(\Delta n)$ around a dislocation outcrop observed in weak-beam images. In weak-beam images taken with the diffraction vectors $\mathbf{g}=0002$ (Fig. 7(b)) and $\mathbf{g}=12 \overline{3} 1$ (Fig. 7(c)), two and one extra thickness-fringes appear on the lower side of the dislocation (indicated by arrowheads in the figure), respectively, whereas no extra fringe is observed for $\mathbf{g}=03 \overline{3} 0$ (Fig. 7(d)) and $\mathbf{g}=$ $21 \overline{3} 0$ (Fig. 7(e)). Thus, the Burgers vector of the dislocation is determined to be [0001]. Dislocations with $\mathbf{b}=[0001]$ are observed not to dissociate into partial dislocations on $(1 \overline{1} 00)$ prismatic plane (Figs. 7(b) and (c)). 


\subsection{2. $[4 \overline{3} \overline{1} 0]$ orientation}

For the [4 $\overline{31} 0]$ orientation, the observed deformation markings are aligned parallel to the traces of the $(2 \overline{11} 2)$ and $(\overline{2} 112)$ planes on the two orthogonal surfaces (Fig. 6(b)), suggesting the operation of $\{2 \overline{11} 2\}$ pyramidal slip. The results of TEM analysis performed to determine the Burgers vector of dislocations on $\{2 \overline{11} 2\}$ pyramidal planes are depicted in Fig. 8. As shown in Fig. 8(a) a dislocation segment marked by $\mathrm{C}$ is dissociated or decomposed into two dislocations A and B in a TEM foil cut parallel to the (2112) slip plane. Contrast analysis to determine their Burgers vectors was carried out in a framed area of Fig. 8(a). All dislocations $\mathrm{A}, \mathrm{B}$ and $\mathrm{C}$ are invisible in a weak-beam image taken with the diffraction vector $\mathbf{g}$ $=03 \overline{3} 0$ (Fig. 8(c)). Dislocations marked with A are invisible also for $\mathbf{g}=\overline{3} 300$ (Fig. 8(d)), indicating their Burgers vector is $[000 \overline{1}]$. The standard $\mathbf{g} \cdot \mathbf{b}$ rule suggests that the Burgers vectors for both dislocations $B$ and $C$ are parallel to the $[2 \overline{1} \overline{1} w$ ] directions since they are invisible for $\mathbf{g}=03 \overline{3} 0$ as shown in Fig. 8(c), but visible for the other imaging conditions. The Burgers vector of the parent dislocation $C$ is then inferred to be $1 / 3[\overline{2} 11 \overline{3}]$ since it must be on the $(\overline{2} 112)$ slip plane with the shortest repeat distance of the lattice. The Burgers vector of the dislocation $\mathrm{B}$ is deduced to be $1 / 3[\overline{2} 110]$ based on the following reaction scheme:

$$
1 / 3[\overline{2} 11 \overline{3}] \rightarrow[000 \overline{1}]+1 / 3[\overline{2} 110]
$$

Since the Burgers vector of $[000 \overline{1}], 1 / 3[\overline{2} 110]$ are not on the observed ( $\overline{2} 112)$ slip plane, they are likely to form as a result of climb decomposition of a dislocation with $\mathbf{b}=1 / 3[\overline{2} 11 \overline{3}]$. It is thus concluded that the $\{2 \overline{11} 2\} 1 / 3<2 \overline{113}>$ pyramidal slips are operative in specimens compressed along the [4 $\overline{31} 0]$ direction and that the dislocations with $\mathbf{b}=1 / 3[\overline{2} 11 \overline{3}]$ are climb-decomposed into two perfect dislocations with $\mathbf{b}_{1}=[000 \overline{1}]$ and $\mathbf{b}_{2}=1 / 3[\overline{2} 110]$.

\subsection{3. [0001] and [2 $\overline{1} \overline{1} 24]$ orientations}

For the [0001] orientation, deformation markings are usually wavy and they are sometimes in the form of thick bands, as shown in Fig. 6(c). The markings are inclined by less than $10^{\circ}$ from the traces of the (0001) plane on two orthogonal surfaces. It is, however, very difficult to determine unambiguously slip planes by performing the trace analysis, because mainly of their wavy nature. Based on the assumption that the high symmetry of the compression axis [0001] makes many equivalent slip systems operating simultaneously and forming wavy deformation markings, similar deformation experiments were carried out for single crystals with the loading axis parallel to the [ $\left[\begin{array}{lll}2 & \overline{1} & 24\end{array}\right]$ orientation, which is about $10^{\circ}$ tilted away from the [0001] orientation in order to determine the operating slip planes by trace analysis, as the results are shown in Fig. 9. The deformation markings observed are aligned

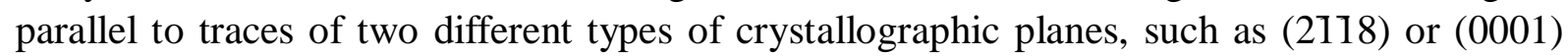

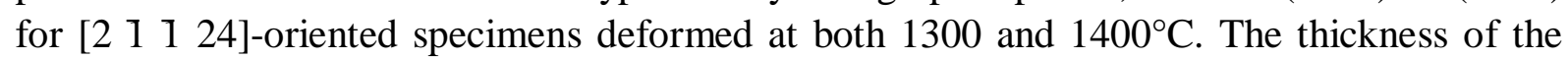
deformation bands increase with increasing temperature.

The orientation difference between regions inside and outside the deformation band parallel to the $(2 \overline{11} 8)$ plane on the $(01 \overline{1} 0)$ surface of the sample deformed at $1400^{\circ} \mathrm{C}$ was examined by Electron backscatter diffraction (EBSD), as shown in Fig. 10. Figs. 10(a) and (b) show the orientation maps representing the surface normal and compression axis directions, respectively. The compression axis direction in the region of the deformation band is approximately $20^{\circ}$ tilted away from that in the region outside of the band, while the surface normal direction is virtually the same for both regions. The change in the compression axis direction occurs abruptly at the boundary between regions inside and outside the deformation band. This indicates that the deformation band is rotated by approximately $20^{\circ}$ about [01 $\left.\overline{1} 0\right]$, as the orientation relationship between the two regions is indicated in Fig. 10(c). As clearly 
seen in the figure, there exist some mirror relationships between the two regions with two different reflection planes; the $(\overline{2} 118)$ habit plane and also with the plane perpendicular to the $[\overline{8} 44 \overline{3}]$ direction. Thus, the deformation band with the $(\overline{2} 118)$ habit plane is determined to be a deformation twin of the compound-type with the twinning elements $K_{1}=(\overline{2} 118)$ and $\eta_{1}=$ $[\overline{8} 44 \overline{3}]$. On the basis of crystallography of deformation twinning, we deduce the other twinning elements $K_{2}, \eta_{2}$ and the twinning shear $s$, as follows: the normal of the $K_{2}$ plane must be close to $\eta_{1}$ for twinning shear to be realistically small and possesses rational and low indices [28, 29]. The most reasonable choice of $K_{2}$ for the twin was determined to be $(\overline{2} 110)$, the plane normal is tilted about $10^{\circ}$ away from $\eta_{1}:$ [ $\left.\overline{8} 44 \overline{3}\right]$. Finally, $\eta_{2}$ and the twinning shear $s$ were determined to be $\eta_{2}=[0001]$ and $s=0.35$.

Fig. 11 shows the result of a similar EBSD analysis performed for the deformation band parallel to the (0001) plane on the (0110) surface of the specimen deformed at $1400^{\circ} \mathrm{C}$. The orientation difference between the adjacent analysis points on the line between A and B in Fig. 11(a) as well as the accumulated values of the orientation difference are plotted in Fig. 11(b). In contrast to the deformation band parallel to the (2118) plane, the orientation of the deformation bands parallel to (0001) varies gradually with a detectable step of less than $1^{\circ}$. The orientation distribution of low-indexed poles within the deformation band indicates that the orientation change occurs with the rotation axis close to the [21ㅣㄹ direction, as shown in Fig. 11(c). Thus, it is concluded that the deformation band parallel to the (0001) plane is a kink band.

\section{Discussion}

\subsection{Operative slip systems}

In the present study, three different types of deformation modes, such as $\{1 \overline{1} 00\}$ [0001] prismatic slip, $\{2 \overline{11} 2\} 1 / 3<2 \overline{113}>$ pyramidal slip and $\{2 \overline{11} 8\}<8 \overline{443}>$ twinning were identified for the first time to operate in $\mathrm{Ti}_{5} \mathrm{Si}_{3}$ at temperatures above $1300^{\circ} \mathrm{C}$. However, we did not observe $\{1 \overline{1} 02\}<\overline{1} 101>$ twinning, which was reported previously by Umakoshi and Nakashima [11]. The critical resolved shear stresses (CRSS's) for these deformation modes calculated with the corresponding Schmid factors are plotted in Fig. 12 as a function of temperature together with those for $\{1 \overline{1} 01\}<1 \overline{1} 0 \overline{2}>$ twinning reported by Umakoshi and Nakashima [11]. The values of the CRSS decrease steeply with increasing temperature for all considered deformation modes. The values of CRSS for $\{1 \overline{1} 00\}$ [0001] prismatic slip are considerably lower than those for $\{2 \overline{11} 2\} 1 / 3<2 \overline{113}>$ pyramidal slip but are comparable to those for $\{2 \overline{11} 8\}<8 \overline{443}>$ twinning. It is worth mentioning that the values of the CRSS for $\{1 \overline{1} 00\}[0001]$ prismatic slip presently identified are comparable to those of $\{1 \overline{1} 02\}<\overline{1} 101>$ twinning reported by Umakoshi and Nakashima [11]. The orientation ranges where these deformation modes are operative are similar to each other.

It is important to discuss how the identified deformation modes (slip systems) in $\mathrm{Ti}_{5} \mathrm{Si}_{3}$ are selected on the basis of anisotropic elasticity theory of dislocations. For a dislocation with a certain Burgers vector, the crystallographic plane for which the self-energy is a minimum or where the critical resolved shear stress for dislocation glide is the lowest one [30]. The total energy per unit length of a straight dislocation in an elastically anisotropic crystal is given by

$$
E=\frac{K b^{2}}{4 \pi} \ln \frac{R}{r_{0}},
$$

where $K$ is the energy factor, $b$ is the magnitude of the Burgers vector, $R$ is the radius of the dislocation strain field and $r_{0}$ is the radius of the dislocation core [30]. The energy factor $K$ is a function of the elastic constants of the crystal and varies with the orientation of the dislocation line with respect to the Burgers vector. Since the logarithmic factor in eqn. (2) is 
insensitive to the exact value of $R / r_{0}$, the total energy $E$ is primarily controlled by the orientation dependence of $K$. The analytical solution of the energy factor $K$ for hexagonal crystals has been given by Foreman [31] and Teutonico [32]. Eshelby [30] has furthermore introduced a measure of the width of an edge dislocation core defined as

$$
\xi=\frac{1}{2} K_{e} s_{66}^{\prime} d,
$$

where $K_{\mathrm{e}}$ is the energy factor for the edge dislocation, $s_{66}{ }_{66}$ is the compliance referred to the dislocation axis, in which the $x_{3}$ axis is set parallel to the dislocation line and $d$ is the interplanar distance of the slip plane. The ratio $\xi / b$ would serve as a measure of the ease of the dislocation glide instead of $d / b$ for an isotropic crystal since the Peierls stress $\tau_{\mathrm{p}}$ for an elastically anisotropic crystal has been given as [30, 33, 34]

$$
\tau_{p}=2 K_{e} \exp \left(-4 \pi \frac{\xi}{b}\right)
$$

The energy factor, elastic compliance constants referred to the dislocation axis, $\xi$ factor, $\xi / b$ ratio and Peierls stress for an edge dislocation are calculated for each slip system using the elastic constants obtained in the present study and are summarized in Table 4. In Eshelby's criterion, the slip system with a large $\xi / b$ value is selected, since the Peirels stress is expected to be the lowest one [30]. The amount of the $\xi / b$ values for various slip systems is the same as that of the $d / b$ values. Among the various slip systems listed up in Table 4, the $\{1 \overline{1} 00\}$ [0001] slip system has the largest $\xi / b$ value and hence is expected to be selected. This is exactly what is observed in experiments of the present study. Since the Peierls stress for the $\{1 \overline{1} 00\}[0001]$ slip system is by far lower than those for other slip systems, their activation is expected to be very difficult as confirmed by the experiment. However, when a crystal orientation is selected so that the $\{1 \overline{1} 00\}[0001]$ slip system can not geometrically operate, $\{2 \overline{11} 2\} 1 / 3<2 \overline{113}>$ pyramidal slip occurs because this slip system has the largest $\xi / b$ value among all possible pyramidal slip systems.

\subsection{Kink bands}

Deformation bands observed parallel to (0001) in [0001]- and [2 $\overline{1} \overline{1}$ 24]- oriented specimens are concluded to be kink bands, since the orientation change within the band occurs gradually with the rotation axis of [21ㅣㄹ. The formation of similar kink bands has been observed in single crystals of the hexagonal closed-packed (hcp) metals as an accommodation mechanism for deformation twins [35, 36]. In these hcp metals, kink bands have been considered to form by the predominant activation of the easiest slip system of the $(0001)<11 \overline{2} 0>$-type, even under the loading condition where the resolved shear stress for the slip system is initially zero, accompanied by the lattice rotation about the $<1 \overline{1} 00>$ direction, i.e. about the line direction of the edge dislocation [36, 37]. For $\mathrm{Ti}_{5} \mathrm{Si}_{3}$, the $\{1 \overline{1} 00\}<0001>$ slip system is the easiest one to operate. The lattice rotation is expected to occur about the $<11 \overline{2} 0>$ direction corresponding to the line direction of the $<0001>$ edge dislocation and the boundary of the band is expected to be initially parallel to basal plane (0001) by analogy of the kink band formation in hcp metals. This is in agreement with the observation of the kink band, indicating that the kink band in $\mathrm{Ti}_{5} \mathrm{Si}_{3}$ is formed as a complementary deformation mode to accommodate the strain caused by the formation of the other type of deformation modes, i.e. deformation twinning, as in the case of many hcp metals.

\subsection{Atomic movements for the $\{2 \overline{118}\}<8 \overline{443}>$ twinning}

Finally we will discuss the atomic movements that occur during $\{2 \overline{11} 8\}<8 \overline{443}>$ twinning. Since $\mathrm{Ti}_{5} \mathrm{Si}_{3}$ is an intermetallic compound with a complex D8 $8_{8}$-type of crystal 
structure, the twinning mechanism is very complicated when compared to those in intermetallic superlattice compounds, which are formed with an ordered arrangement of different atomic species in fcc (face-centered cubic), bcc (body-centered cubic) and hcp lattices. In the case of complex crystal structures containing many atoms in the unit cell, the twinning process can be divided into two steps: (1) uniform shear of a lattice and (2) shuffles of atoms to the nearest twin sites. In the classical twinning theory, it is convenient to introduce a motif unit and a motif lattice, which is generally different from the unit cell and contains many lattice points of the unit cell. Let us consider the projection of the atomic structure of the $(2 \overline{118})[8 \overline{443}]$ twin along the normal of the shear plane $S$. For this, we introduce a motif lattice defined by the three translation vectors of $\eta_{1}:$ [8443], $\eta_{2}$ : [0001], and the normal of the shear plane $S:[0 \overline{1} 10]$. Fig. 13(a) indicates the relationship between the unit cell of $\mathrm{Ti}_{5} \mathrm{Si}_{3}$ (dotted line) and the motif lattice (thick line) projected along the normal of the shear plane $S$. The motif lattice contains four unit-cell lattice points, on which a single motif unit is allocated. The number $(q)$ of the lattice $K_{1}$ planes traversed by the primitive lattice vector of $\eta_{2}$ is 4 . We first consider the movements of these lattice points in the motif lattice. The comparison between the lattice points in the sheared matrix of the motif lattice and the twinned one indicates that only two of the four lattice points in the matrix of the motif lattice are moved to adequate lattice points of the twinned lattice by a simple twinning shear. The remaining two lattice points must be recovered to maintain the crystal structure of $\mathrm{Ti}_{5} \mathrm{Si}_{3}$. The former and latter lattice points are assigned as $\alpha$ and $\beta$ in Fig. 13(a), respectively. The subscripts $\mathrm{M}, \mathrm{S}$ and $\mathrm{T}$ in Fig. 13(a) correspond to the matrix, the sheared matrix and the twin, respectively. In general, the twinning systems with the smaller magnitude of shear $s$ and/or $q$ are considered to be activated preferentially from the viewpoint of lattice shear [38-40]. The relatively simple lattice shear with a small number of $q$ is considered to be one of the reasons for the operation of the $\{2 \overline{11} 8\}<8 \overline{443}>$ twinning in $\mathrm{Ti}_{5} \mathrm{Si}_{3}$. The twinning systems with $q=4$ are similarly observed for many other metallic materials [38]. Secondly, we consider the shuffles of atoms. In the case of the deformation twin with $q=4$, it is sufficient to consider two different types of atomic shuffles around the two different types of the unit-cell lattice points in the motif lattice [38]. In order to consider the atomic shuffles, we consider the atomic arrangements in the unite cell of $\mathrm{Ti}_{5} \mathrm{Si}_{3}$ in greater details. As presented by the [0001]-projection of the crystal structure of $\mathrm{Ti}_{5} \mathrm{Si}_{3}$ in Fig. 13(b), there are fourteen atomic layers in a single repeating distance along the $[0 \overline{1} 10]$ direction, i.e. the normal of the plane of shear $S$. Because of the mirror symmetry on the $S$ plane, the number of the atomic layer type to be considered is reduced to eight, as indicated in Fig. 13(b). It is sufficient to consider the atomic movements in these eight types of shear planes to describe quantitatively the twining process. For simplicity, a motif unit is divided into eight different atomic layers of the $S$ plane as shown in Fig.13(c). Considering the complex atomic arrangements of $\mathrm{Ti}_{5} \mathrm{Si}_{3}$, it would be easy and also reasonable to assume that the shuffles of atoms occur within each atomic layer, i.e. shuffles of atoms normal to the $S$ plane have not been considered. Possible atomic movements of each motif unit are deduced by comparing the atomic positions of the sheared matrix and twin, as shown in Figs. 13(c) and 13(d). The atomic movements with the shortest translation are selected as the most probable ones. The possible movements of atoms for motif units located on two types of lattice points $\alpha$ and $\beta$ are indicated in Fig. 13(d) and are summarized in Table 5. There are some atomic shuffles with the translation increment of about $0.2-0.3 \mathrm{~nm}$, which is comparable with the shortest interatomic distance of about $0.25 \mathrm{~nm}$. This implies that the formation of the $\{2 \overline{11} 8\}<8 \overline{443}>$-twin is greatly influenced by the atomic shuffling motion to recover the crystal structure [41, 42]. This is one of the reason why $\{2 \overline{11} 8\}<8 \overline{443}>$ twinning is operative only at very high temperature above $1400^{\circ} \mathrm{C}$. 


\section{Conclusion}

1. Three different types of operating deformation modes, such as $\{1 \overline{1} 00\}$ [0001] prismatic slip, $\{2 \overline{11} 2\} 1 / 3<2 \overline{113}>$ pyramidal slip and $\{2 \overline{11} 8\}<8 \overline{443}>$ twinning were identified in $\mathrm{Ti}_{5} \mathrm{Si}_{3}$ at deformation temperatures above $1300^{\circ} \mathrm{C}$ for the first time.

2. The CRSS steeply decreases with increasing temperature for all deformation modes. The CRSS for $\{1 \overline{1} 00\}[0001]$ prismatic slip is considerably lower than that for $\{2 \overline{11} 2\} 1 / 3<2 \overline{113}>$ pyramidal slip at all temperatures but are comparable to those for $\{2 \overline{11} 8\}<8 \overline{443}>$ twinning.

3. Kink bands formed parallel to the (0001) plane as a complementary deformation modes which accommodate the strain caused by the $\{2 \overline{11} 8\}<8 \overline{443}>$ deformation twin, accompanied by the orientation change within the band occurring with the $<11 \overline{2} 0>$ rotation axis corresponding to the line direction of the $<0001>$ edge dislocation.

4. Room temperature elastic constants were determined as follows; $\mathrm{c}_{11}=285 \mathrm{GPa}, \mathrm{c}_{33}=268$ $\mathrm{GPa}, \mathrm{c}_{12}=106 \mathrm{GPa}, \mathrm{c}_{13}=53.4 \mathrm{GPa}, \mathrm{c}_{44}=93.0 \mathrm{GPa}$ and $\mathrm{c}_{66}=89.3 \mathrm{GPa}$. The bulk modulus $(\mathrm{K})$, shear modulus $(\mathrm{G})$ and Young's modulus (E) were estimated by Hill's average method to be $140 \mathrm{GPa}, 96 \mathrm{GPa}$ and $234 \mathrm{GPa}$, respectively. The negative Cauchy pressure and small Poisson's ratio indicate the significance of directional atomic bonding and the intrinsic brittleness of this compound.

\section{Acknowledgements}

This work was partly supported by the Global COE (Center of Excellence) Program of International Center for Integrated Research and Advanced Education in Materials Science from the Ministry of Education, Culture, Sports, Science and Technology (MEXT), Japan.

\section{References}

[1] Yamaguchi M, Inui H, Ito K. Acta mater 2000; 48: 307

[2] Vasudevan AK, Petrovic JJ. Mater Sci Engng 1992; A155: 1

[3] Ito K, Inui H, Shirai Y, Yamaguchi M. Philos Mag A 1995; 72: 1075

[4] Maloy SA, Mitchell TE, Heuer AH. Acta metall mater 1995; 43: 657

[5] Bewlay BP, Jackson MR, Zhao JC, Subramanian PR. Metall Mater Trans 2003; 34A: 2043

[6] Meyer MK, Akinc M. J Am Ceram Soc 1996; 79: 938

[7] Williams JJ, Akinc M. Oxid Met 2002; 58: 57

[8] Akinc M, Meyer MK, Kramer MJ, Thom AJ, Huebsch JJ, Cook B. Mater Sci Engng 1999; A261: 16

[9] Schneibel JH, Ritchie RO, Kruzic JJ, Tortorelli PF. Metall Mater Trans 2005; 36A: 525

[10] Frommeyer G, Rosenkranz R, Lüdecke C. Z Metallk 1990; 81: 307

[11] Umakoshi Y, Nakashima T. Scripta metall mater 1994; 30: 1431

[12] Zhang L, Wu J. Acta mater 1998; 46: 3535

[13] Wu JS, Beaven PA, Wagner R. Scripta metall mater 1990; 24: 207

[14] Vojt ěch D, Novák M, Novák P, Lejček P, Kopeček J. Mater Sci Engng 2008; A489: 1

[15] Sun FS, Cao CX, Kim SE, Lee YT, Yan MG. Metall Mater Trans 2001; 32A: 1233

[16] Sun FS, Froes FH. Mater Sci Engng 2003; A345: 262

[17] Suehiro Y, Ameyama K. J Mater Proc Tech 2001; 111: 118

[18] Williams JJ, Kramer MJ, Akinc M, Malik SK. J Mater Res 2000; 15: 1773

[19] Tanaka K, Koiwa M. High Temp Mater Process 1999; 18: 323

[20] Pettivor DG. Mater Sci Technol 1992; 8: 345

[21] Hill R. Proc Phys Soc London A 1952; 65: 349 
[22] Pugh SF. Philos Mag 1954; 45: 823

[23] Inui H, Moriwaki M, Ito K, Yamaguchi M. Philos Mag A 1998; 77: 375

[24] Inui H, Moriwaki M, Okamoto N, Yamaguchi M. Acta mater 2003; 51: 1409

[25] Yoshimi K, Yoo MH, Wereszczak AA, Borowicz SM, George EP, Zee RH. Scripta Mater 2001; 45: 1321

[26] Alexander H, Haasen P. Solid State Phys 1968; 22: 28

[27] Ishida Y, Ishida H, Kohra K, Ichinose H. Philos Mag A 1980; 42: 453

[28] Cahn RW, Acta Metall 1953; 1: 49

[29] De Angelis RJ, Cohen JB. Some Crystallographic Techniques for the Study of Mechanical Twinning and their Application to Shock-Induced Twinning in Copper. In: Reed-Hill RE, Hirth JP, Rogers HC, editors, Deformation Twinning, New York (NY): Gordon and Breach Science, 1964, p. 430.

[30] Eshelby JD. Philos Mag 1949; 40: 903

[31] Foreman AJE. Acta Metall 1955; 3: 322

[32] Teutonico LJ. Mater Sci Engng 1970; 6: 27

[33] Cottrell AH. Dislocations and Plastic Flow in Crystals. London: Oxford University Press; 1953

[34] Christian JW, Vitek V. Rep Prog Phys 1970; 33: 307

[35] Hartt WH, Reed-Hill RE. Trans Metall Soc AIME 1968; 242: 2207

[36] Crocker AG, Abell JS. Philos Mag 1976; 33: 305

[37] Hess JB, Barrett CS. Trans Metall Soc AIME 1949; 185: 599

[38] Christian JW, Mahajan S. Prog Mater Sci 1995; 39: 1

[39] Yoo MH, Fu CL, Lee JK. J Phys III 1991; 1: 1065

[40] Crocker AG, Bevis M, The Crystallography of Deformation Twinning in Titanium. In: Jaffee R, Promised N, editors, The Science Technology and Application of Titanium, Oxford: Pergamon, 1970, p. 453.

[41] Christian JW, Laughlin DE. Acta Metall 1988; 36: 1617

[42] Kishida K, Takahama Y, Inui H. Acta Mater 2004; 52: 4941 
Table 1. The highest Schmid factors for various deformation modes in $\mathrm{Ti}_{5} \mathrm{Si}_{3}$ single crystals with four different loading axis orientations tested in this study.

\begin{tabular}{cccccc}
\hline \multirow{2}{*}{ Deformation mode } & \multicolumn{4}{c}{ Loading axis orientation } \\
\cline { 3 - 6 } & & {$[2 \overline{2} 05]$} & {$[4 \overline{31} 0]$} & {$[0001]$} & {$[2 \overline{11} 24]$} \\
\hline Basal slip & $(0001) 1 / 3<2 \overline{11} 0>$ & 0.433 & 0 & 0 & 0.175 \\
& $(0001)<1 \overline{1} 00>$ & 0.500 & 0 & 0 & 0.152 \\
Prism slip & $\{1 \overline{1} 00\}[0001]$ & 0.500 & 0 & 0 & 0.152 \\
& $\{1 \overline{1} 00\} 1 / 3<\overline{11} 20>$ & 0.217 & 0.500 & 0 & 0.014 \\
& $\{2 \overline{11} 0\}[0001]$ & 0.433 & 0 & 0 & 0.175 \\
Pyramidal slip & $\{2 \overline{11} 0\}<01 \overline{1} 0>$ & 0.217 & 0.500 & 0 & 0.014 \\
& $\{2 \overline{11} 2\} 1 / 3<2 \overline{113}>$ & 0.233 & 0.432 & 0.468 & 0.500 \\
& $\{10 \overline{1} 1\} 1 / 3<2 \overline{113}>$ & 0.310 & 0.479 & 0.444 & 0.487 \\
\hline Twinning & $\{2 \overline{11} 1\} 1 / 3<2 \overline{116}>$ & 0.237 & 0.438 & 0.475 & 0.500 \\
\hline & $\{1 \overline{1} 02\}<\overline{1} 101>$ & 0.364 & 0.324 & - & - \\
& $\{2 \overline{11} 8\}<8 \overline{443}>$ & 0.428 & - & 0.168 & 0.322 \\
\hline
\end{tabular}

Table 2. Single crystal elastic constants and anisotropy parameters for $\mathrm{Ti}_{5} \mathrm{Si}_{3}$ at room temperature.

\begin{tabular}{ccccccccc|}
\hline $\begin{array}{c}c_{11} \\
(\mathrm{GPa})\end{array}$ & $\begin{array}{c}c_{33} \\
(\mathrm{GPa})\end{array}$ & $\begin{array}{c}c_{12} \\
(\mathrm{GPa})\end{array}$ & $\begin{array}{c}c_{13} \\
(\mathrm{GPa})\end{array}$ & $\begin{array}{c}c_{44} \\
(\mathrm{GPa})\end{array}$ & $\begin{array}{c}c_{66} \\
(\mathrm{GPa})\end{array}$ & $c_{33} / c_{11}$ & $\left(c_{11}+c_{33}-2 c_{13}\right) / 4 c_{44}$ & $c_{44} / c_{66}$ \\
\hline 285 & 268 & 106 & 53.4 & 93.0 & 89.3 & 0.94 & 1.20 & 1.04 \\
\hline
\end{tabular}

Table 3. Polycrystalline elastic moduli (bulk $(B)$, shear $(G)$, Young's $(E)$ ), Poisson's ration $(v)$ and Cauchy pressures for $\mathrm{Ti}_{5} \mathrm{Si}_{3}$ at room temperature.

\begin{tabular}{cccccc}
\hline \multirow{2}{*}{$\mathrm{B}(\mathrm{GPa})$} & $\mathrm{G}(\mathrm{GPa})$ & $\mathrm{E}(\mathrm{GPa})$ & $v$ & \multicolumn{2}{c}{ Cauchy pressure } \\
\cline { 5 - 6 } & & & & $c_{12}-c_{66}(\mathrm{GPa})$ & $c_{13}-c_{44}(\mathrm{GPa})$ \\
\hline 140 & 96 & 234 & 0.22 & 16.7 & -39.6 \\
\hline
\end{tabular}

Table 4. The energy factor, elastic compliance constants referred to the dislocation axis, $\xi$ factor, $\xi / b$ ratio and Peierls stress for an edge dislocation of each possible slip system in $\mathrm{Ti}_{5} \mathrm{Si}_{3}$.

\begin{tabular}{lllllllll}
\hline Slip systems & $\begin{array}{l}d \\
(\mathrm{~nm})\end{array}$ & $\begin{array}{l}b \\
(\mathrm{~nm})\end{array}$ & $\begin{array}{l}d / b \\
\text { Basal }\end{array}$ & $\begin{array}{l}K_{\mathrm{e}} \\
(\mathrm{GPa})\end{array}$ & $\begin{array}{l}s_{66}^{\prime} \\
\left(10^{-12}\right. \\
\left.\mathrm{GPa}^{-1}\right)\end{array}$ & $\xi / b$ & $\begin{array}{l}\tau_{\mathrm{p}} \\
(\mathrm{GPa})\end{array}$ \\
\hline \multirow{3}{*}{ Prism } & $\{1 \overline{1} 00\}[0001]$ & 0.155 & 0.515 & 0.301 & 123.9 & 10.8 & 0.201 & 19.9 \\
& $\{1 \overline{1} 00\} 1 / 3<\overline{11} 20>$ & 0.155 & 0.746 & 0.208 & 122.6 & 11.2 & 0.143 & 40.8 \\
& $\{2 \overline{11} 0\}[0001]$ & 0.086 & 0.515 & 0.166 & 123.9 & 10.8 & 0.111 & 61.5 \\
& $\{2 \overline{11} 2\} 1 / 3<2 \overline{113}>$ & 0.097 & 0.906 & 0.108 & 126.5 & 9.37 & 0.064 & 113.6 \\
& $\{10 \overline{1} 1\} 1 / 3<2 \overline{113}>$ & 0.058 & 0.906 & 0.064 & 103.3 & 9.53 & 0.032 & 138.7 \\
& $\{2 \overline{11} 1\} 1 / 3<2 \overline{116}>$ & 0.066 & 1.272 & 0.052 & 125.2 & 9.32 & 0.030 & 170.7 \\
\hline
\end{tabular}


Table 5. Summary of possible atomic shuffling in $\{2 \overline{11} 8\}<8 \overline{443}>$ twinning illustrated in Fig. 13(d).

\begin{tabular}{cccc}
\hline \multirow{2}{*}{$\begin{array}{c}\text { Layer } \\
\text { No. }\end{array}$} & Atom & \multicolumn{2}{c}{ Atomic shuffling around the lattice point } \\
\cline { 3 - 4 } & & $\alpha$ & $\beta$ \\
\hline 1 & $\mathrm{Ti}(2)$ & $\pm 0.620 \eta_{2}(0.319 \mathrm{~nm})$ & $\pm 0.120 \eta_{2}(0.062 \mathrm{~nm})$ \\
& $\mathrm{Si}$ & $\pm 0.308 \eta_{2}(0.158 \mathrm{~nm})$ & $\pm 0.193 \eta_{2}(0.099 \mathrm{~nm})$ \\
\hline 2 & $\mathrm{Ti}(2)$ & $\pm 0.060 \eta_{1}(0.182 \mathrm{~nm})$ & $\pm 0.060 \eta_{2}(0.031 \mathrm{~nm})$ \\
\hline 3 & $\mathrm{Ti}(1)$ & $\pm 0.250 \eta_{2}(0.129 \mathrm{~nm})$ & $\pm 0.250 \eta_{2}(0.129 \mathrm{~nm})$ \\
\hline 4 & $\mathrm{Si}$ & $\pm 0.404 \eta_{2}(0.208 \mathrm{~nm})$ & $\pm 0.096 \eta_{2}(0.050 \mathrm{~nm})$ \\
\hline 5 & $\mathrm{Si}$ & $\pm 0.346 \eta_{2}(0.175 \mathrm{~nm})$ & $\pm 0.154 \eta_{2}(0.079 \mathrm{~nm})$ \\
\hline 6 & $\mathrm{Ti}(1)$ & $0(0 \mathrm{~nm})$ & $0(0 \mathrm{~nm})$ \\
\hline 7 & $\mathrm{Ti}(2)$ & $\pm 0.310 \eta_{2}(0.160 \mathrm{~nm})$ & $\pm 0.190 \eta_{2}(0.098 \mathrm{~nm})$ \\
\hline 8 & $\mathrm{Ti}(2)$ & $\pm 0.370 \eta_{2}(0.191 \mathrm{~nm})$ & $\pm 0.130 \eta_{2}(0.067 \mathrm{~nm})$ \\
& $\mathrm{Si}$ & $\pm 0.058 \eta_{1}(0.174 \mathrm{~nm})$ & $\pm 0.058 \eta_{2}(0.174 \mathrm{~nm})$ \\
\hline
\end{tabular}

(a)

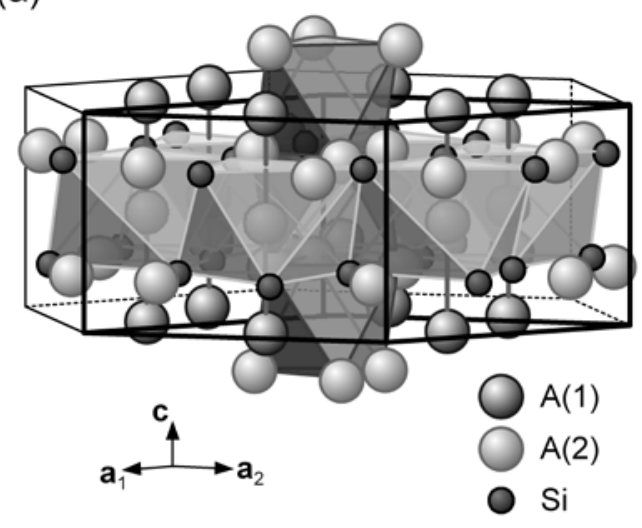

(b) [0001] projecction

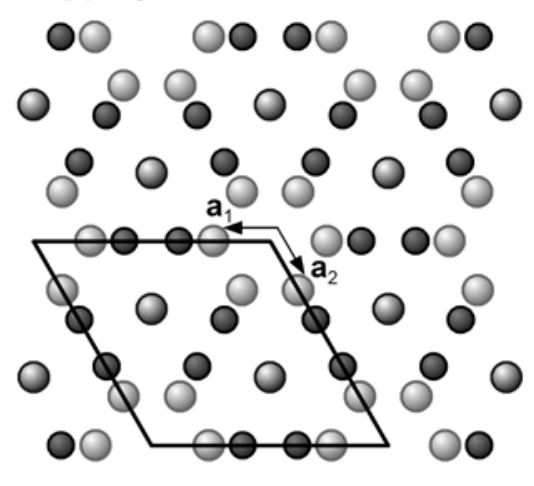

(d) $[01 \overline{1} 0]$ projecction

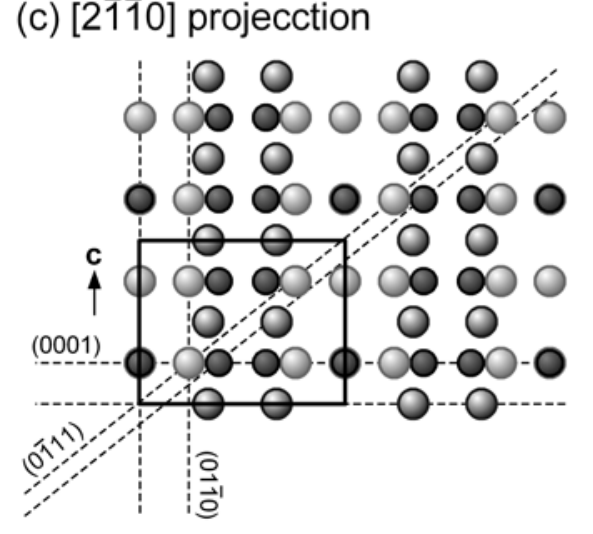

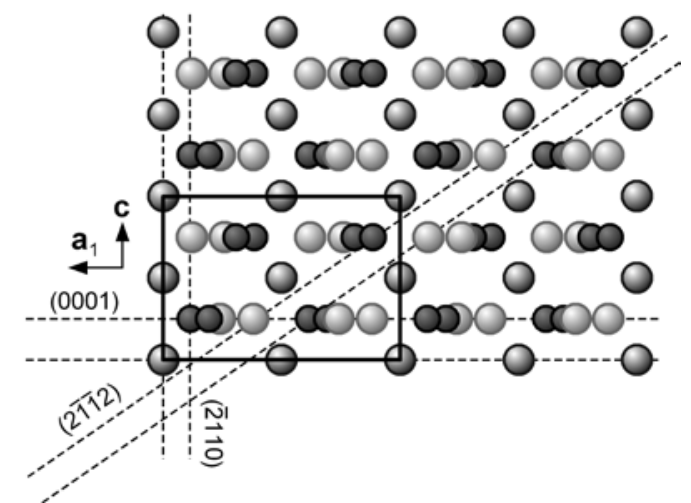

Fig. 1. Crystal structure of $\mathrm{Ti}_{5} \mathrm{Si}_{3}$ : (b) [0001], (c) [2 $\left.\overline{11} 0\right]$ and (d) [01 $\left.\overline{1} 0\right]$ projections. 


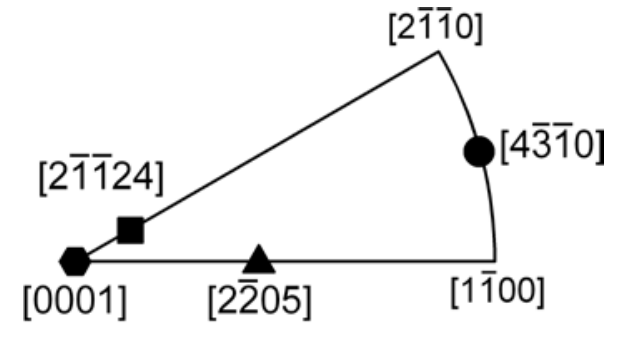

Fig. 2. Standard stereographic projection of the loading axis orientations.

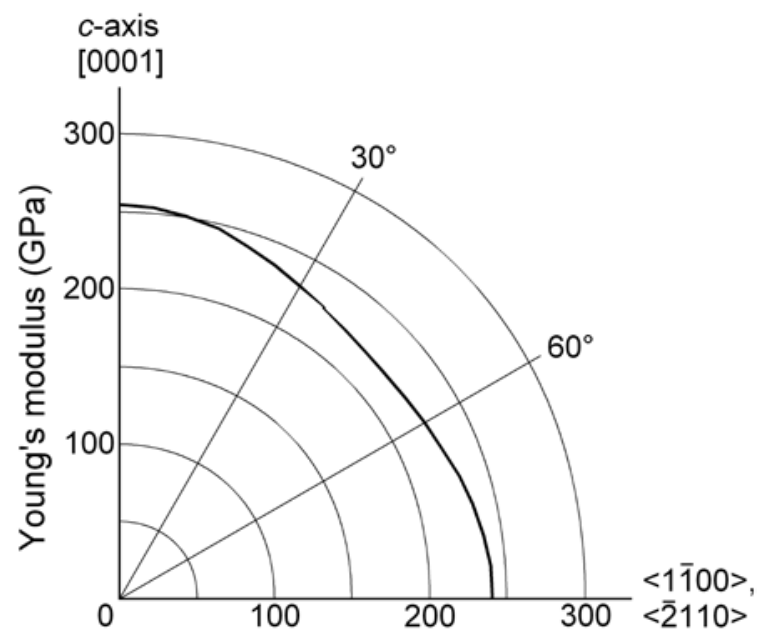

Fig. 3. Orientation dependence of the Young's modulus for single crystalline $\mathrm{Ti}_{5} \mathrm{Si}_{3}$ at room temperature. (a) $[2 \overline{2} 05]$ orientation

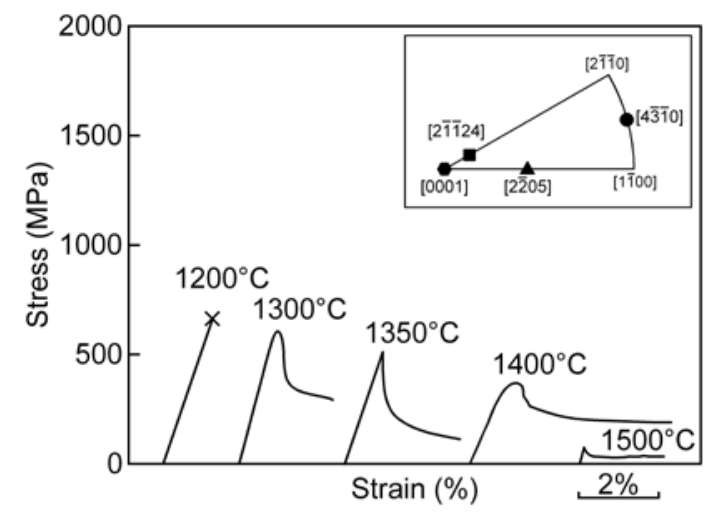

(c) [0001] orientation

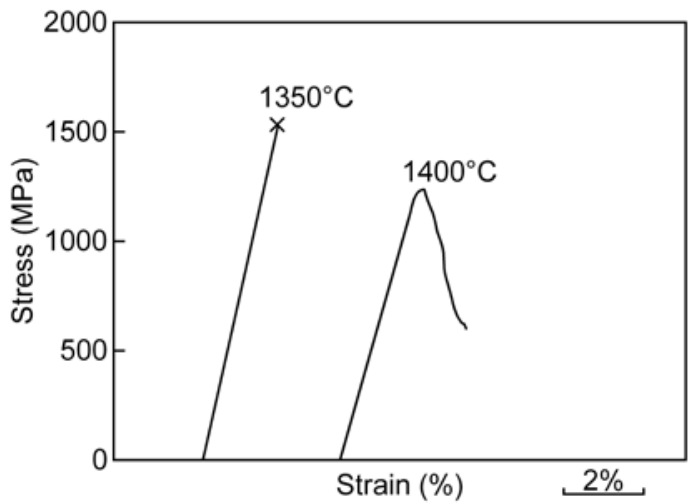

(b) $[4 \overline{3} \overline{1} 0]$ orientation

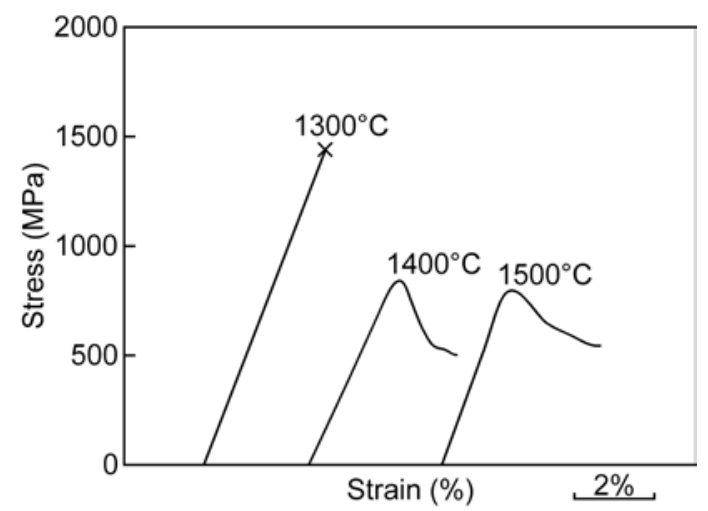

(d) $[2 \overline{1} \overline{1} 24]$ orientation

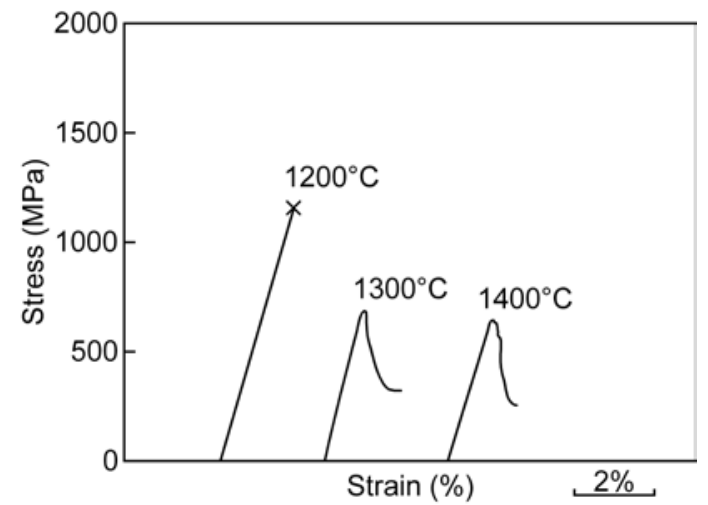

Fig. 4. Typical engineering stress-strain curves of $\mathrm{Ti}_{5} \mathrm{Si}_{3}$ single crystals with (a) [2205], (b)

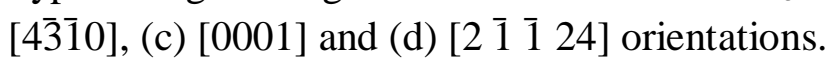




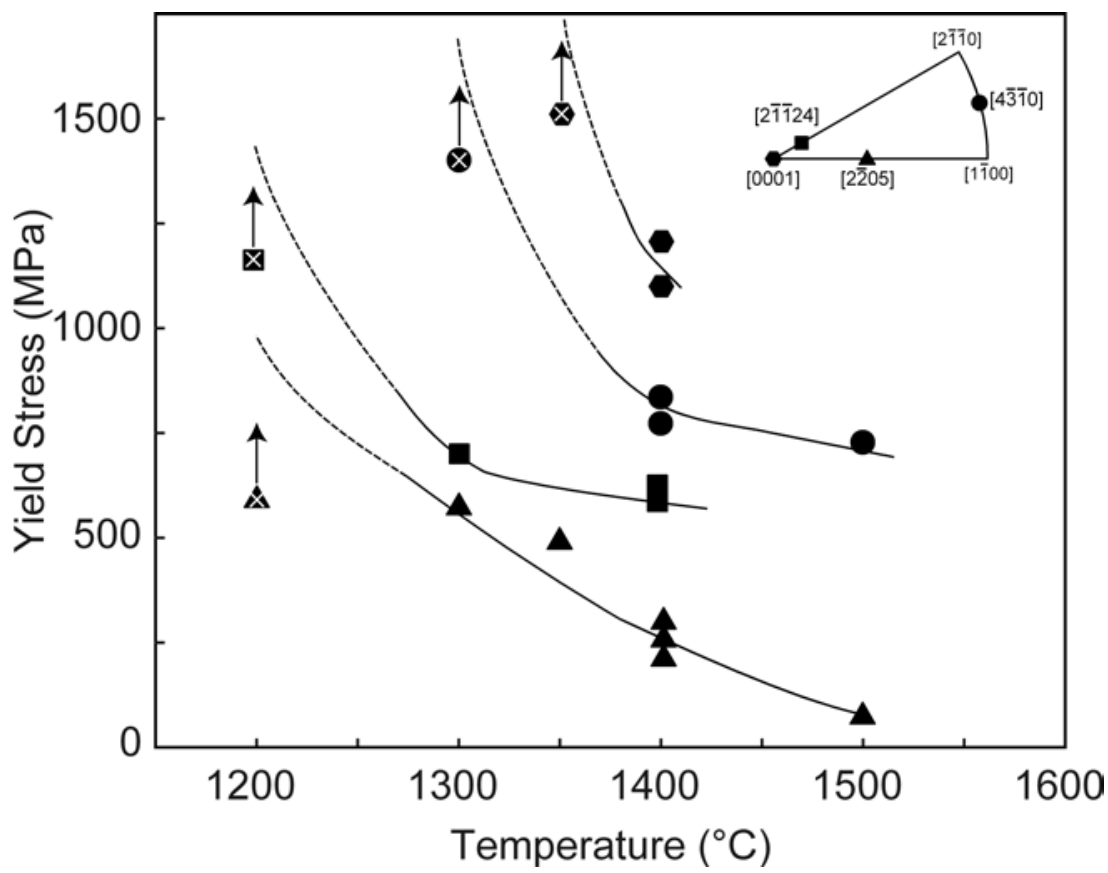

Fig. 5. Temperature dependence of the yield stress for $\mathrm{Ti}_{5} \mathrm{Si}_{3}$ single crystals with four different loading axis orientations.
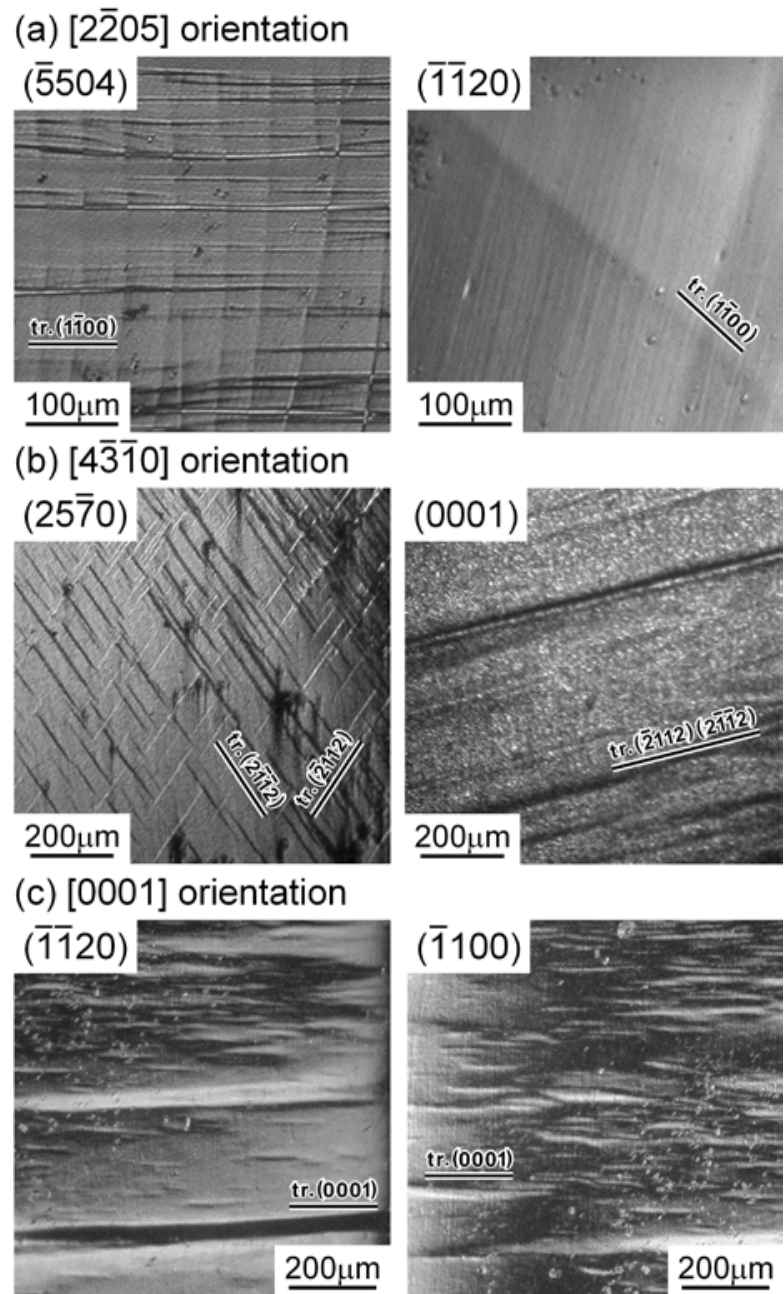

Fig. 6. Deformation markings observed on two orthogonal surfaces of $\mathrm{Ti}_{5} \mathrm{Si}_{3}$ single crystals

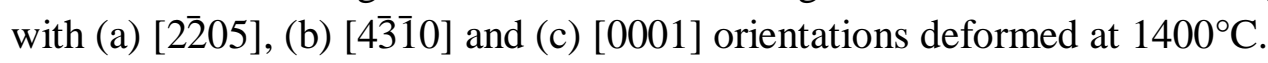



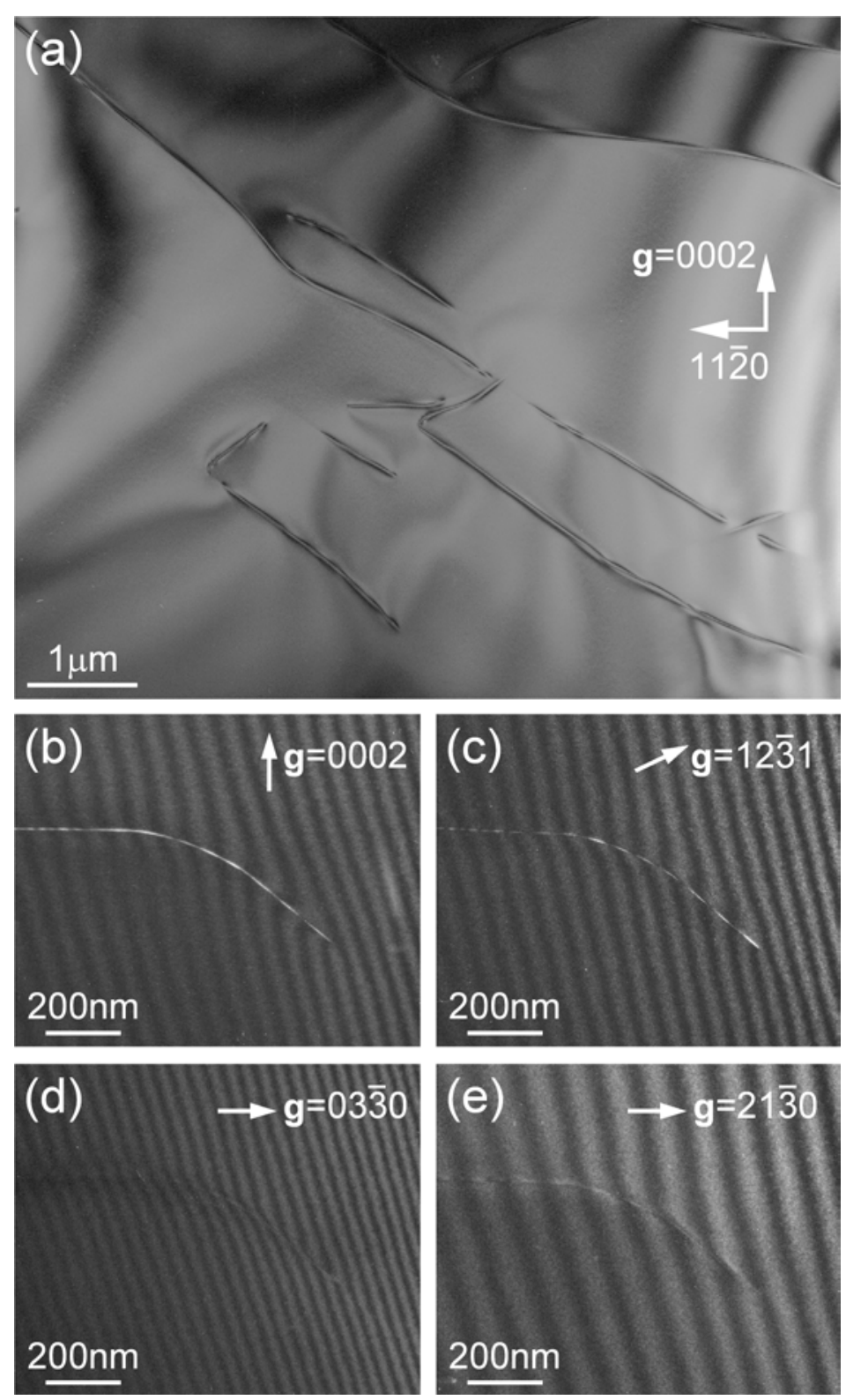

Fig. 7. (a) Bright-field and (b-e) weak-beam images of the dislocation structure in a [2205]-oriented $\mathrm{Ti}_{5} \mathrm{Si}_{3}$ single crystal deformed at $1400^{\circ} \mathrm{C}$. The diffraction vector (g) used is indicated in each of the images. 

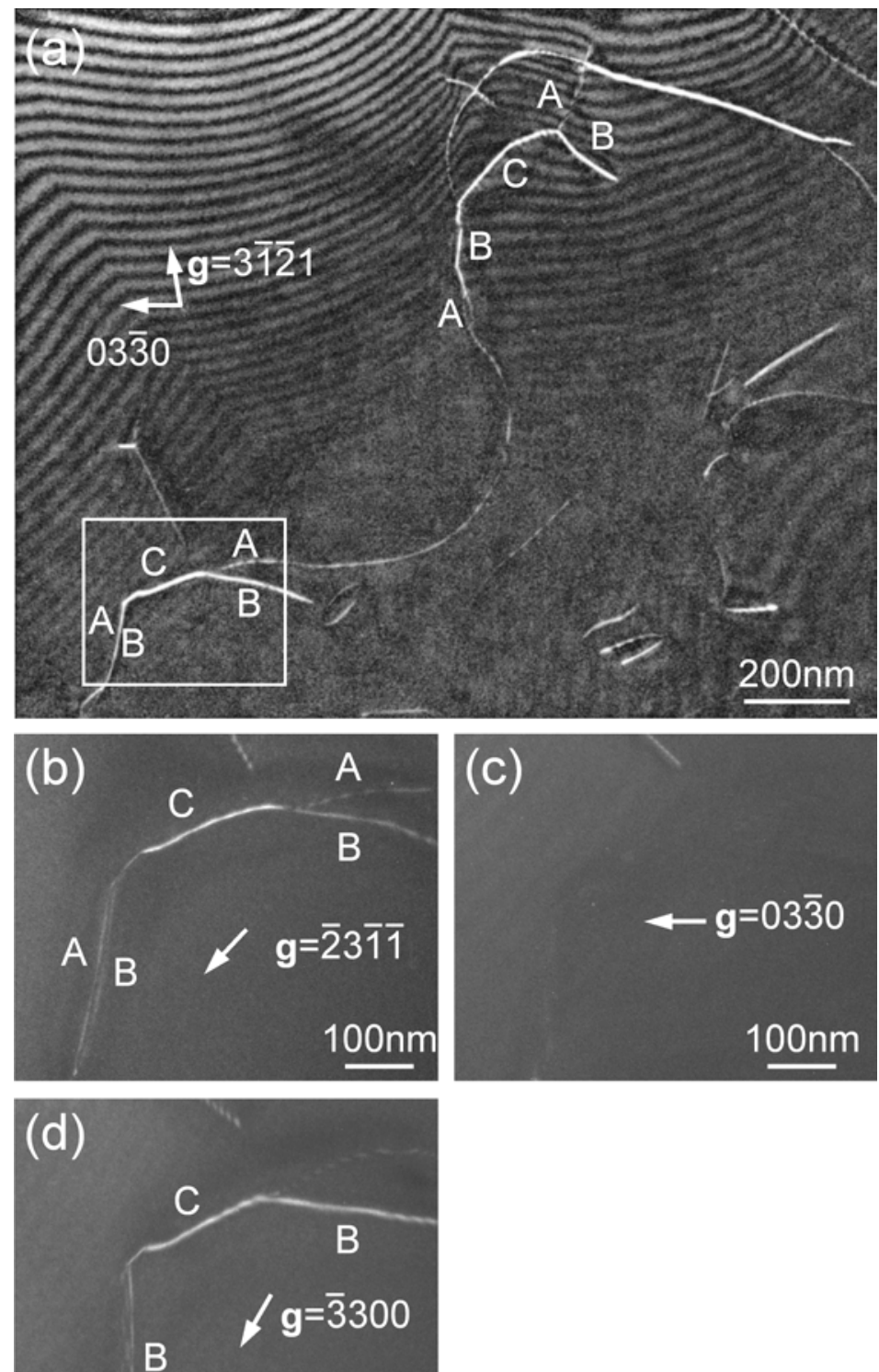

$100 \mathrm{~nm}$

Fig. 8. Weak-beam images of a dislocation structure in a [4 $\overline{31} 0]$-oriented $\mathrm{Ti}_{5} \mathrm{Si}_{3}$ single crystal deformed at $1400^{\circ} \mathrm{C}$. The diffraction vector (g) used is indicated in each of the images. 
(a) $1300^{\circ} \mathrm{C}$
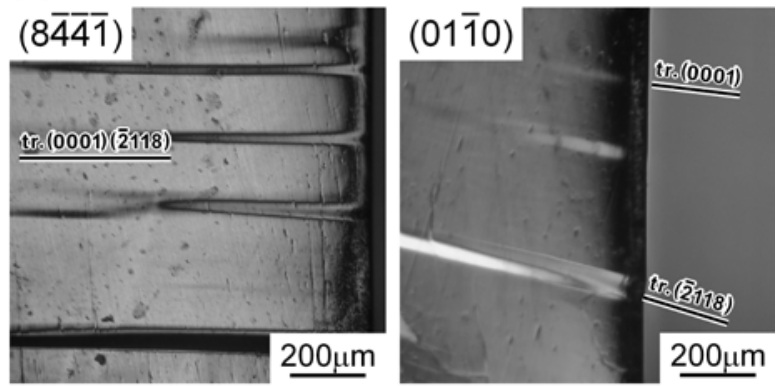

(b) $1400^{\circ} \mathrm{C}$
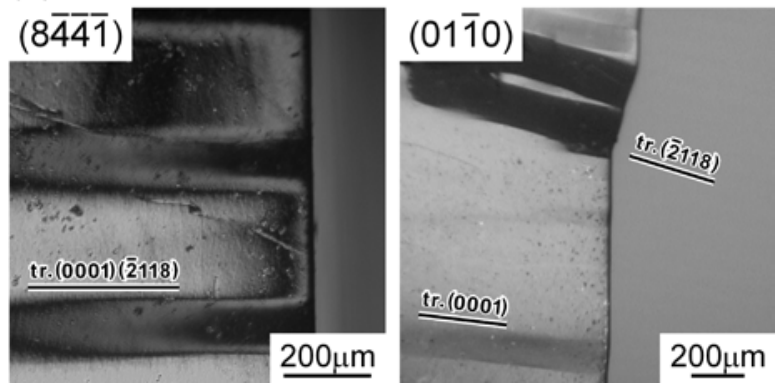

Fig. 9. Deformation markings observed on two orthogonal surfaces in [ $\left[\begin{array}{llll}2 & \overline{1} & \overline{1} & 24\end{array}\right]$ - oriented $\mathrm{Ti}_{5} \mathrm{Si}_{3}$ single crystals deformed at (a) 1300 and (b) $1400^{\circ} \mathrm{C}$.
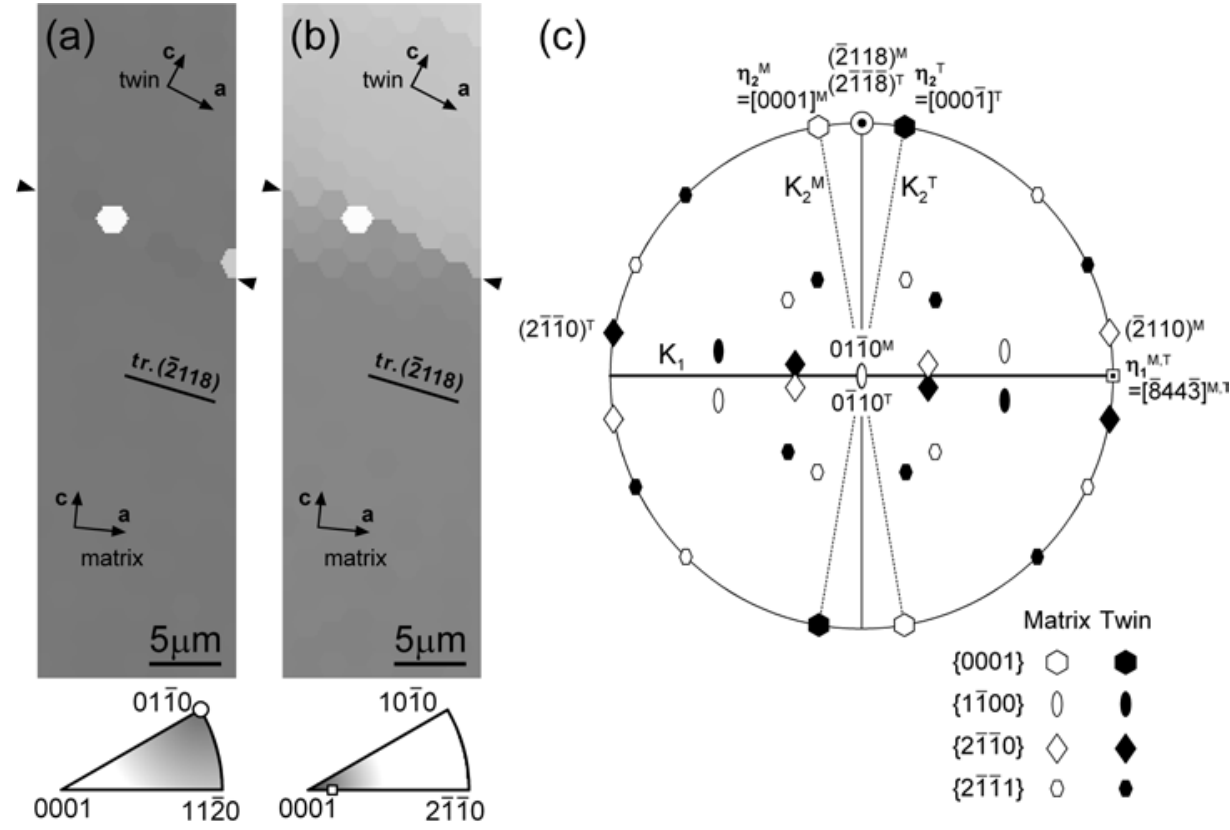

Fig. 10. EBSD analysis of the deformation band with the habit plane parallel to (2118) observed in a [ $\left.\begin{array}{llll}2 & \overline{1} & \overline{1} & 24\end{array}\right]$-oriented $\mathrm{Ti}_{5} \mathrm{Si}_{3}$ single crystal deformed at $1400^{\circ} \mathrm{C}$ in compression. The orientation maps showing (a) the surface normal and (b) compression axis directions. (c) Stereographic projection of the orientation relationship between the two regions inside and outside of the deformation band. 

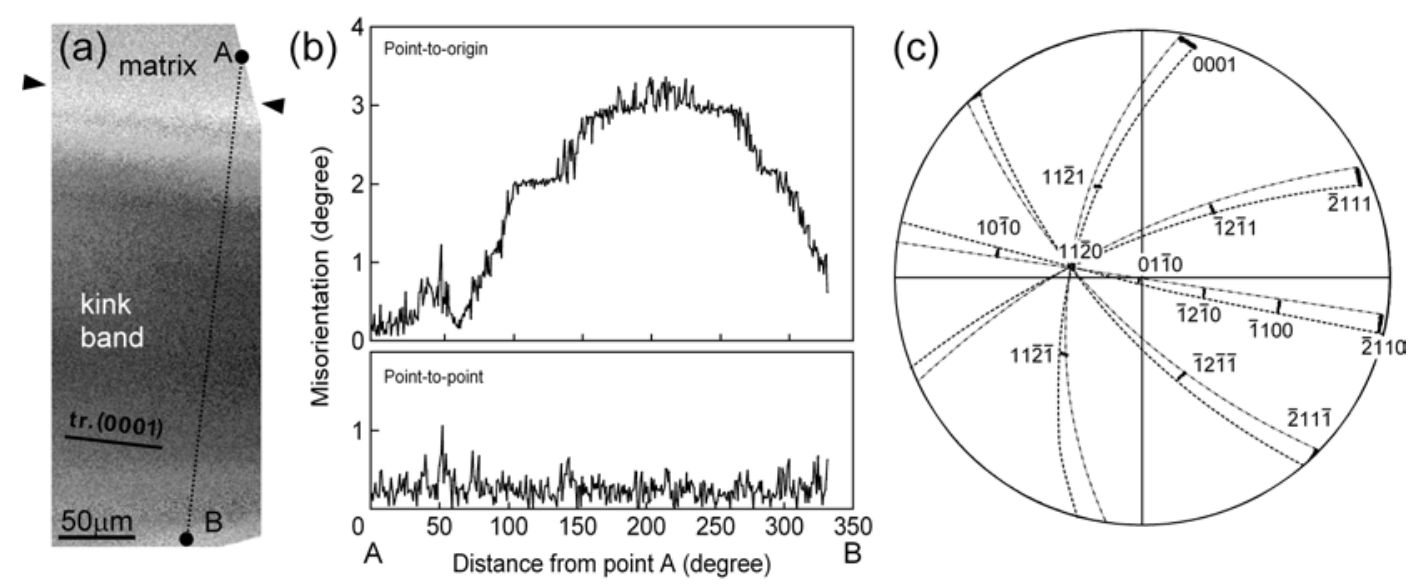

Fig. 11. EBSD analysis of a deformation band with the habit plane parallel to (0001) observed in a [2 $\left.\begin{array}{llll}2 & \overline{1} & 24\end{array}\right]$-oriented $\mathrm{Ti}_{5} \mathrm{Si}_{3}$ single crystal deformed at $1400^{\circ} \mathrm{C}$ in compression. (a) Orientation map showing the surface normal direction. (b) Orientation difference between adjacent analysis points (point-to-point) on the line between A and B in Fig. 11(a) as well as the accumulated values of the orientation difference (point-to-origin) (c) Orientation distribution of low-indexed poles in the deformation band.

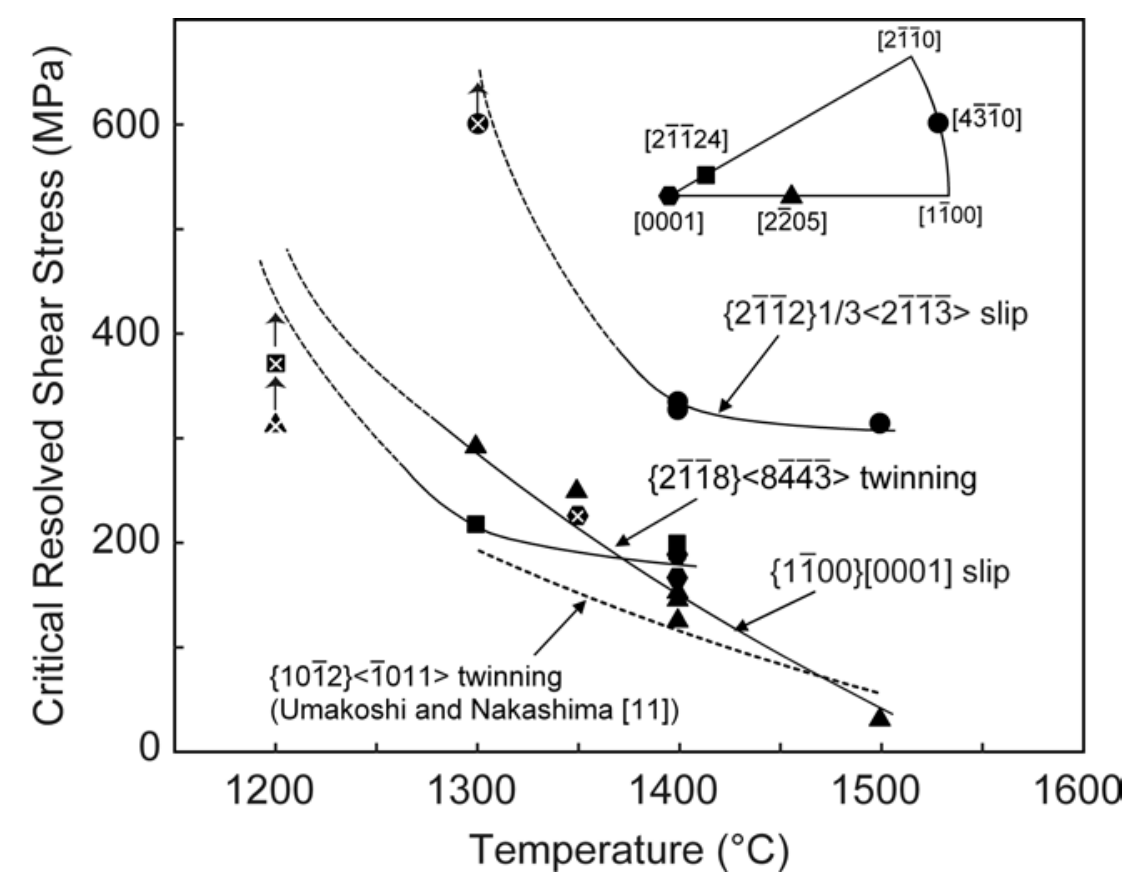

Fig. 12. Temperature dependence of the CRSS for $\{1 \overline{1} 00\}<0001>$ prismatic slip, $\{2 \overline{11} 2\}<2113>$ pyramidal slip in $\mathrm{Ti}_{5} \mathrm{Si}_{3}$ single crystals. The corresponding curve for $\{10 \overline{1} 2\}<\overline{1} 011>$ twinning, which was previously reported by Umakoshi and Nakashima [11], is also indicated. 
(a)

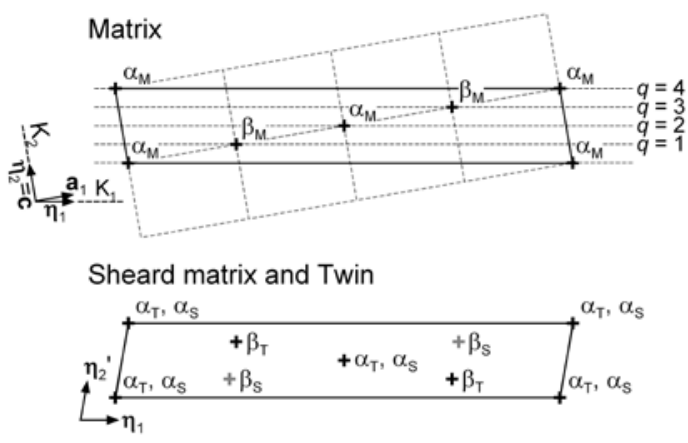

(c)

layer \#1

$(\mathrm{Ti}+\mathrm{Si})$

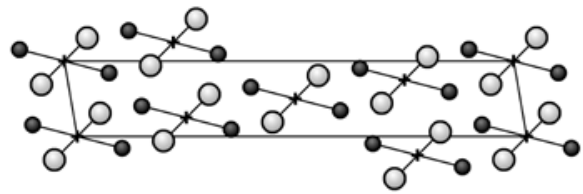

layer \#2

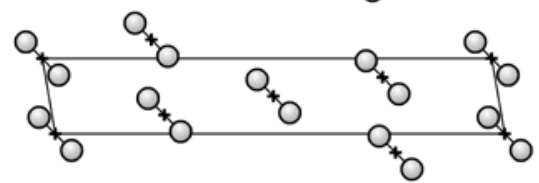

layer \#3

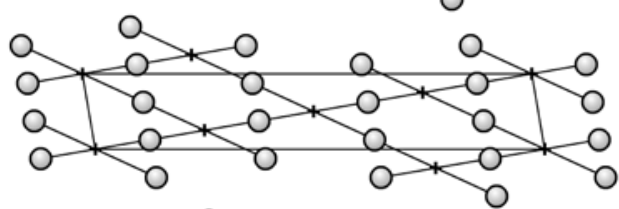

layer \#4

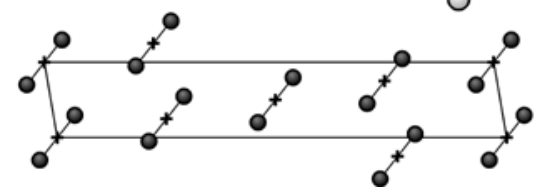

(b)

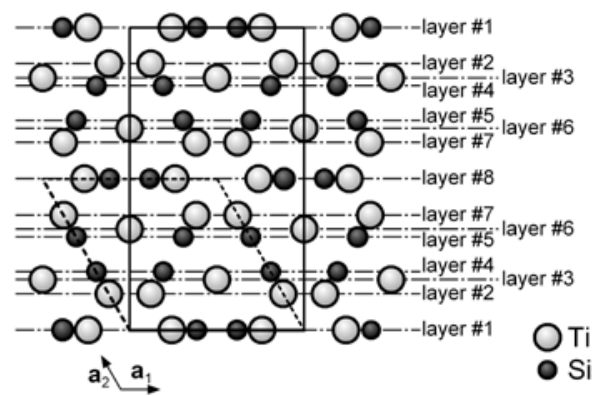

(Si)

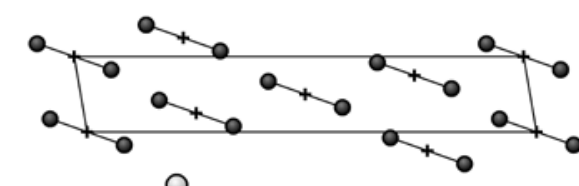

layer \#6

(Ti)

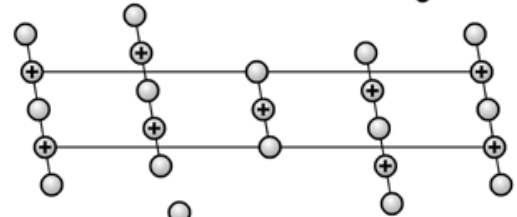

(Ti)

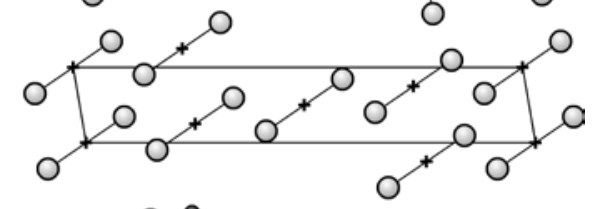

layer \#8

(Ti+Si)

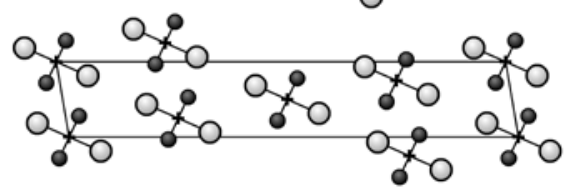

Fig. 13 a-c 
(d) layer \#1

(Si)

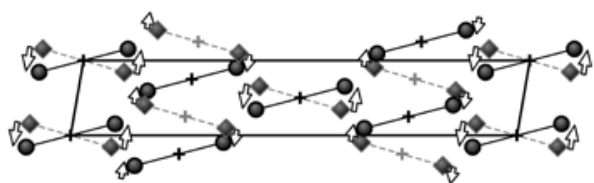

(Ti)

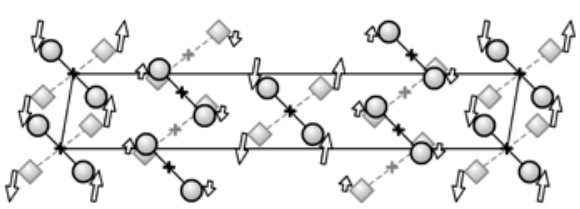

layer \#2

(Ti)

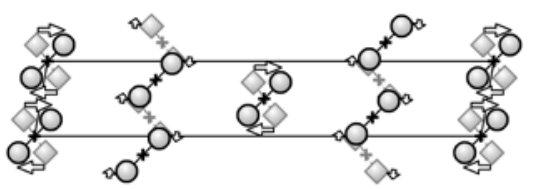

(Ti)

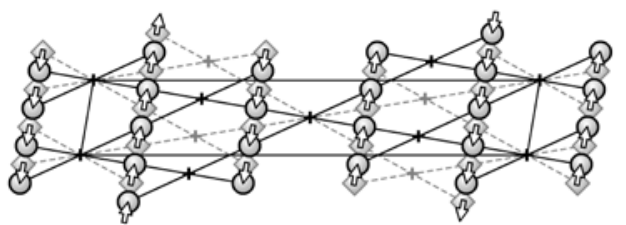

layer \#4

(Si)

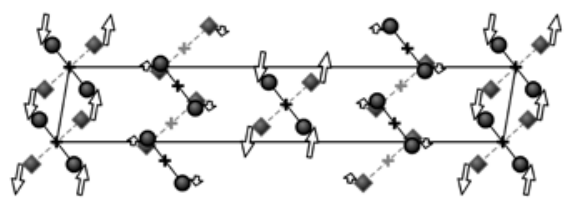

$\mathrm{O} \mathrm{Ti}$ in twin

$\diamond \mathrm{Ti}$ in sheared matrix layer \#5

(Si)

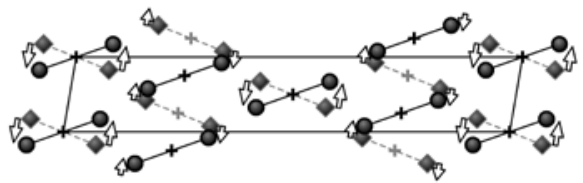

layer \#6

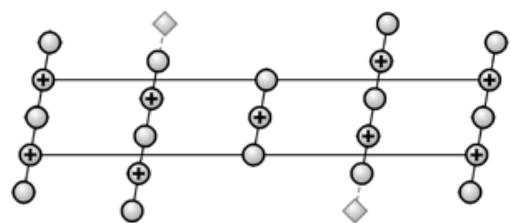

layer \#7

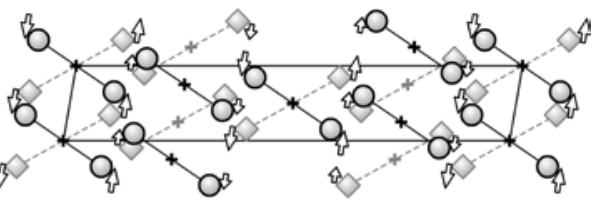

layer \#8

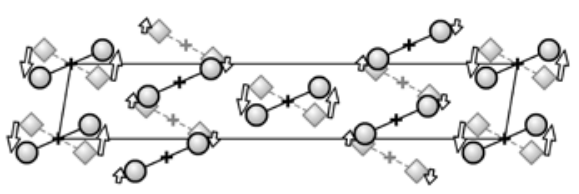

layer \#8

(Si)

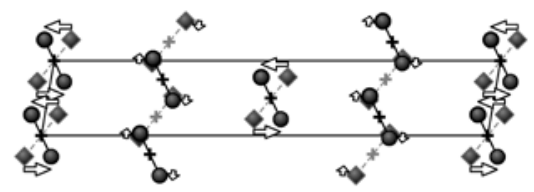

Si in twin

$\checkmark \mathrm{Si}$ in sheared matrix

Fig.13. (a) Relationship between the unit cell of $\mathrm{Ti}_{5} \mathrm{Si}_{3}$ (dotted line) and the motif lattice (thick line) for $\{2 \overline{118}\}<8 \overline{443}>$ twinning projected along the normal of the shear plane $S$, (b) [0001]-projection of the crystal structure, (c) atomic arrangements on eight different atomic layers indicated in (b), and (d) schematic illustration of possible atomic-shuffling mechanism for $\{2 \overline{11} 8\}<8 \overline{443}>$ twinning. 